\title{
Title: Directed ortho-meta'- and meta-meta'-Dimetalations: A Template Base Approach to Deprotonation
}

\author{
Authors: Antonio J. Martínez-Martínez, Alan R. Kennedy, Robert E. Mulvey* and Charles T. \\ O’Hara*
}

\begin{abstract}
Affiliations:
WestCHEM, Department of Pure and Applied Chemistry, University of Strathclyde, Glasgow G1 1XL, UK

*Correspondence to: r.e.mulvey@strath.ac.uk and charlie.ohara@strath.ac.uk.
\end{abstract}

\begin{abstract}
The regioselectivity of deprotonation reactions between arene substrates and basic metalating agents is usually governed by the electronic and/or coordinative characteristics of a directing group attached to the benzene ring. Generally the reaction takes place in the ortho position, adjacent to the substituent. Here we introduce a protocol whereby the metalating agent, a disodium-monomagnesium alkyl-amide, forms a template that extends regioselectivity to more distant arene sites. Depending on the nature of the directing group, ortho-meta' or meta-meta' dimetalation is observed, in the latter case breaking the dogma of ortho metalation. This concept is elaborated through the characterization of both organometallic intermediates and electrophilically quenched products.
\end{abstract}

One Sentence Summary: Development of a template base provides new regioselectivities in metallation reactions of arenes allowing access to key pharmaceutical building blocks.

Main Text: One of the most widely applied chemical reactions is metalation $(1,2)$, whereby an inert carbon-hydrogen $(\mathrm{C}-\mathrm{H})$ bond is transformed to a more reactive carbon-metal $(\mathrm{C}-\mathrm{M})$ bond by a metalating agent. The fundamental importance and vast scope of metalation arise from the ubiquity of the $\mathrm{C}-\mathrm{H}$ bond, one of the most abundant bonds found in nature, which provides a rich sustainable entry point for the synthesis of aromatic chemicals, natural products and organicbased materials. However this abundance of C-H bonds poses a formidable challenge to synthetic chemists in, how can metalation reactions be made regioselective, that is to deprotonate specific $\mathrm{C}-\mathrm{H}$ bonds without reacting with other $\mathrm{C}-\mathrm{H}$ bonds in the same molecule? One answer arrived in "directed ortho-metalation (DoM)" (3-6), the seminal concept to date in metalation chemistry. First introduced independently by Gilman (7) and Wittig (8), and then greatly extended by Beak (9), Mortier (10), Hoppe $(11,12)$ and Snieckus $(13,14)$, amongst others, DoM relies primarily on the substitution within the aromatic substrate undergoing the $\mathrm{C}-\mathrm{H}$ to $\mathrm{C}-\mathrm{M}$ transformation. To induce the $\mathrm{D} o \mathrm{M}$ reaction, this substrate must contain a directing metalation group (DG) that can activate an adjacent (ortho) $\mathrm{C}-\mathrm{H}$ bond towards metalation either by 
providing the incoming Lewis acidic metalating agent with a Lewis basic docking site (coordination effect) and/or weakening this bond through electron-withdrawing inductive properties (electronic effect) (Fig. 1). Depending on their relative coordinating and electron withdrawing ability, DGs can be weak, moderate or strong ortho-directors.

In general, the DoM concept applies irrespective of which metalating agent is employed whether it be an organolithium reagent or one of the new wave of bimetallic formulations [typified by Knochel's (TMP) $\mathrm{MgCl} \cdot \mathrm{LiCl}(15,16)$; TMP is 2,2,6,6-tetramethylpiperidide]. Emphasising this limited regioselectivity, Schlosser notes in his masterwork on polar organometallic chemistry that "deviations from the ortho rule do exist but are scarce" (2). Beak and Snieckus in their seminal perspective on the "complex-induced proximity effect (CIPE)" (6) explain how lithiation can occur remotely from the ortho position in special cases where the target $\mathrm{C}-\mathrm{H}$ bond is formally remote (though bond connections) but is conformationally in proximity (through space) to the lithium-DG substituent coordination point. Recently, this idea has been elegantly extended to cyclopalladation reactions of certain amines (17), hydrocinnamic acids and toluenes (18), through using conformationally locked substituents that effect meta-activation.

Here we introduce a concept to extend the scope of regioselectivities attainable in aromatic $\mathrm{C}-\mathrm{H}$ metalation chemistry. The innovation lies in controlling the regioselectivity through the structure of the metalating agent rather than the inherent DG characteristics of the aromatic ring substituents.
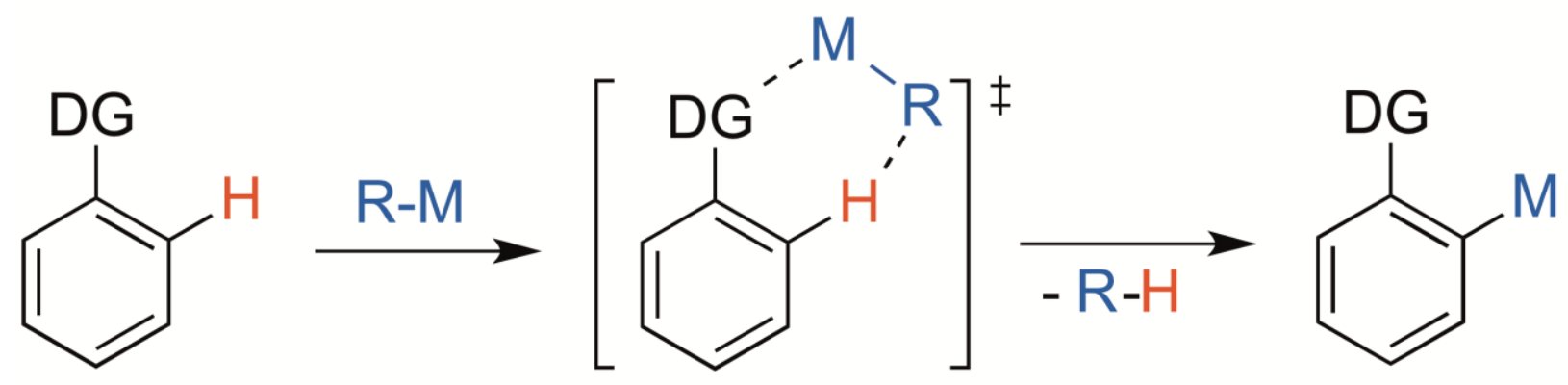

Fig. 1. Mechanism of the substituent directed ortho-metalation.

Recently we established that the donor solvent-free structure of the potassium alkyl-amido magnesiate hexamer $\left[\left\{\mathrm{KMg}(\mathrm{TMP})_{2}\left({ }^{\mathrm{n}} \mathrm{Bu}\right)\right\}_{6}\right] \mathbf{1}_{\mathbf{B u}}$ is capable of metallating benzene, toluene and naphthalene to produce the hexameric areneides $\left[\left\{\mathrm{KMg}(\mathrm{TMP})_{2}(\text { areneide })\right\}_{6}\right] \mathbf{1}_{\text {areneide }}(19)$. This transformation provided strong evidence for a base template mechanism: the six butyl components of $\mathbf{1}_{\mathbf{B u}}$ deprotonate regioselectively one $\mathrm{C}-\mathrm{H}$ bond of six arene molecules to generate $\mathbf{1}_{\text {areneide }}$ inverse crowns, wherein the areneide anions are trapped within the retained hexameric ring framework of the base. Describing such compounds as inverse crowns acknowledges the topological but inverse relation to conventional crown ethers where the Lewis basic $(\mathrm{O}$ heteroatom containing) host rings trap Lewis acidic (metal atom) guests. A donor solvent-free medium (methylcyclohexane) was essential for these templation reactions as without competition 
from lone pair coordinating solvents (e.g., ethers) the pre-inverse-crowns can grow uninterruptedly through polar, but molecular (not infinite) aggregation.

With the sixfold symmetry of $\mathbf{1}_{\mathbf{B u}}$ leading to similarly symmetrical inverse crown products, we thought it prudent to probe the metalating ability of sodium magnesiate " $\left[\mathrm{Na}_{4} \mathrm{Mg}_{2}(\mathrm{TMP})_{6}\left({ }^{\mathrm{n}} \mathrm{Bu}\right)_{2}\right]$ " $\mathbf{2}_{\mathbf{B u}}$ in methylcyclohexane because its lower symmetry might promote different $\mathrm{C}-\mathrm{H}$ deprotonating reactions. Promisingly a preliminary reaction of $\mathbf{2}_{\mathrm{Bu}}$ with naphthalene produced an inverse crown comprising a 12-atom [ $\mathrm{Na}(\mathrm{TTHP}) \mathrm{Na}(\mathrm{TMP}) \mathrm{Mg}(\mathrm{TMP})]$ host ring 3 that trapped a 1,4-dideprotonated naphthalene $\left(1,4-\mathrm{C}_{10} \mathrm{H}_{6}\right)$, though this reaction was complicated by one TMP ligand losing methane to form TTHP (2,2,6-trimethyl-1,2,3,4tetrahydropyridide) $(19,20)$. Although attempts to crystallize $\mathbf{2}_{\mathbf{B u}}$ have been unsuccessful, we have characterized its hydrocarbon solution structure by several NMR spectroscopic methods. Most compelling, DOSY and EXSY NMR spectra show two $n$-butyl-containing species in solution which can be attributed to the existence of a monomer-dimer equilibrium between " $\left[\mathrm{Na}_{2} \mathrm{Mg}(\mathrm{TMP})_{3}\left({ }^{\mathrm{n}} \mathrm{Bu}\right)\right]$ " and its dimer $\mathbf{2}_{\text {Bu }}$ (Fig. S4-S6 and accompanying text). Equilibria of this type are common in polar organometallic chemistry (21). Also, inverse crowns of matching formula $\left[\left\{\mathrm{Na}_{4} \mathrm{Mg}_{2}(\mathrm{TMP})_{6}\right\}\left(\right.\right.$ areneide $\left.\left.^{2-}\right)\right]$ are known to form from in situ mixtures of $\boldsymbol{2}_{\mathbf{B u}}$ with benzene or toluene (22), while similar 12-atom ring motifs can be constructed replacing magnesium by divalent metals of comparable size (Cr, Mn, Fe) (23).

To cover the full range of weak to strong ortho-directors we screened all the representative DoM substrates in Fig. 2 with $\mathbf{2}_{\text {Bu }}$ prepared in methylcyclohexane solution by combining ${ }^{n} \mathrm{BuNa}(24)$, ${ }^{\mathrm{n}} \mathrm{Bu}_{2} \mathrm{Mg}$ and $\mathrm{TMP}(\mathrm{H})$ in a 2:1:3 ratio. Note that we have developed a user-friendly one-pot glovebox-free strategy for the synthesis of $\mathbf{2}_{\mathrm{Bu}}$, which is notably stable as a $0.1 \mathrm{M}$ solution in methylcyclohexane for at least 1 month (25). We began the screening with anisole 4a. 


\section{STRONG}
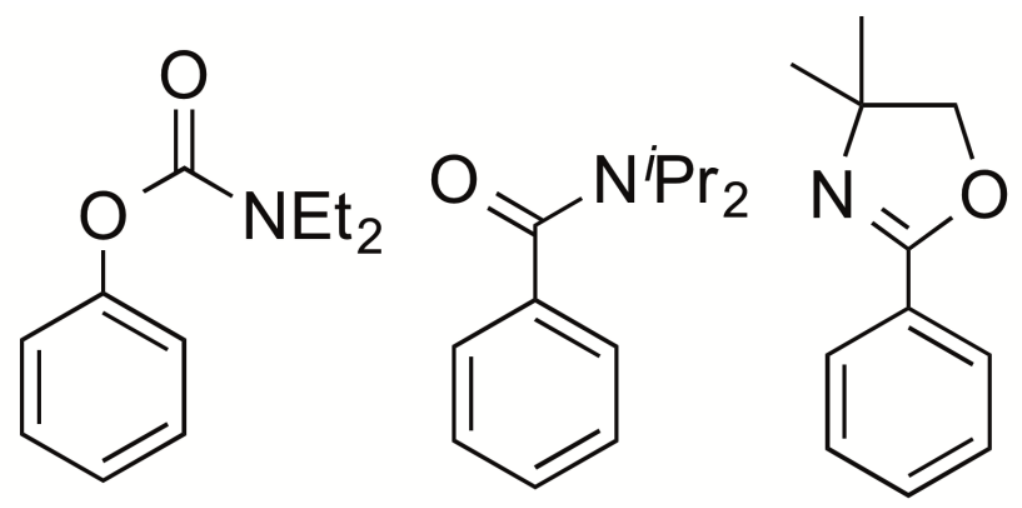

MODERATE
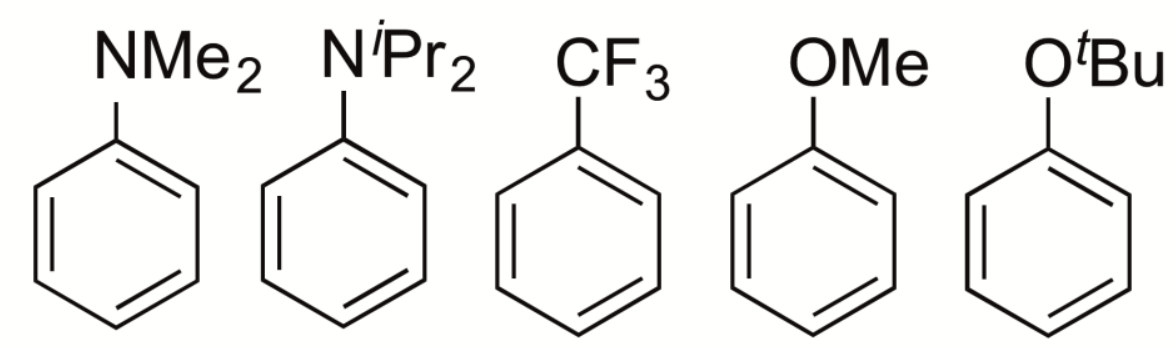

\section{WEAK}
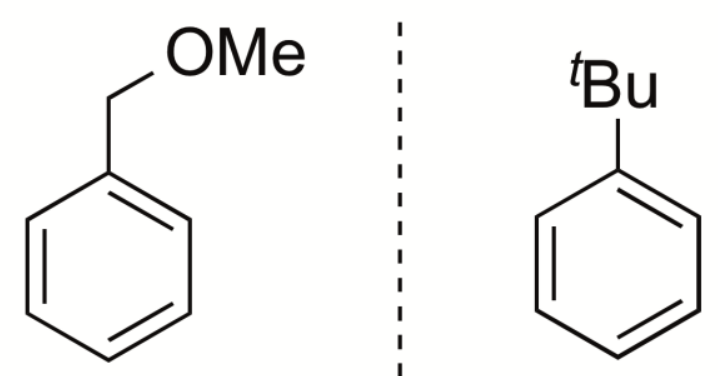

Fig. 2. DG substituted arenes for screening with $\mathbf{2}_{\mathrm{Bu}}$ highlighting their comparative orthodirecting ability.

Anisole, an important scaffold in pharmaceuticals such as the analgesic Tramadol (26) and the antidepressant Moxifetin hydrogen maleate (27), has been a key benchmark reagent in enhancing understanding of $\mathrm{D} o \mathrm{M}$ chemistry. Hitherto it has only been possible to directly metalate anisole at one ortho-position (28-31). Reaction of anisole with $\mathbf{2}_{\mathbf{B u}}$ in methylcyclohexane solution under reflux conditions for 12 hours resulted in 2,5-dimetalation; work-up with $\mathrm{D}_{2} \mathrm{O}$ produced 2,5anisole- $\mathrm{d}_{2} \mathbf{6 a}$ (Table 1 , entry $1,80 \%$ ). To gain insight into the intermediate organometallic chemistry behind this transformation, we undertook an X-ray diffraction study of crystalline 5a that revealed the new inverse crown $\left[\mathrm{Na}_{4} \mathrm{Mg}_{2}(\mathrm{TMP})_{6}\left(\mathrm{C}_{6} \mathrm{H}_{3} \mathrm{OMe}-2,5\right)\right]$ (Fig. 3). Though the X-ray data are of insufficient quality to discuss structural metrics, the metalation sites can be unequivocally assigned to an ortho- and opposite facing meta'-position. 
Table 1. Regioselective 2,5-dimetalation of DG-substituted arene substrates and subsequent electrophilic addition reactions.

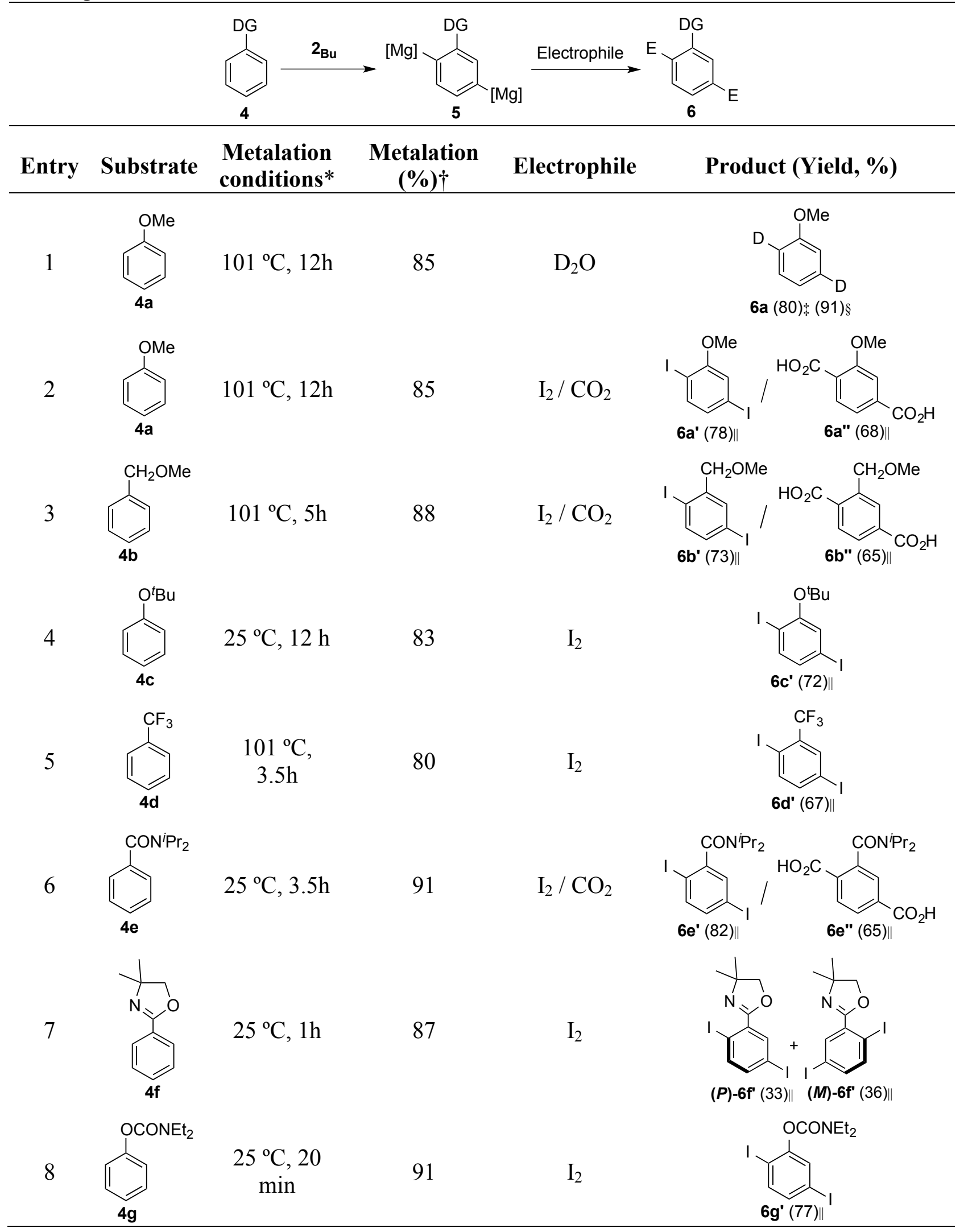


* Metalation conditions (temperature, time). $\dagger$ Extent of 2,5-dimetalation determined by NMR spectroscopy. $\$$ Conversion determined by NMR spectroscopy based on in situ reaction of $\mathbf{2}_{\mathbf{B u}}$ with 4a. $\S$ Isolated yield based on the reaction of crystalline $5 \mathbf{a}$ and $\mathrm{D}_{2} \mathrm{O}$. || Isolated yield.

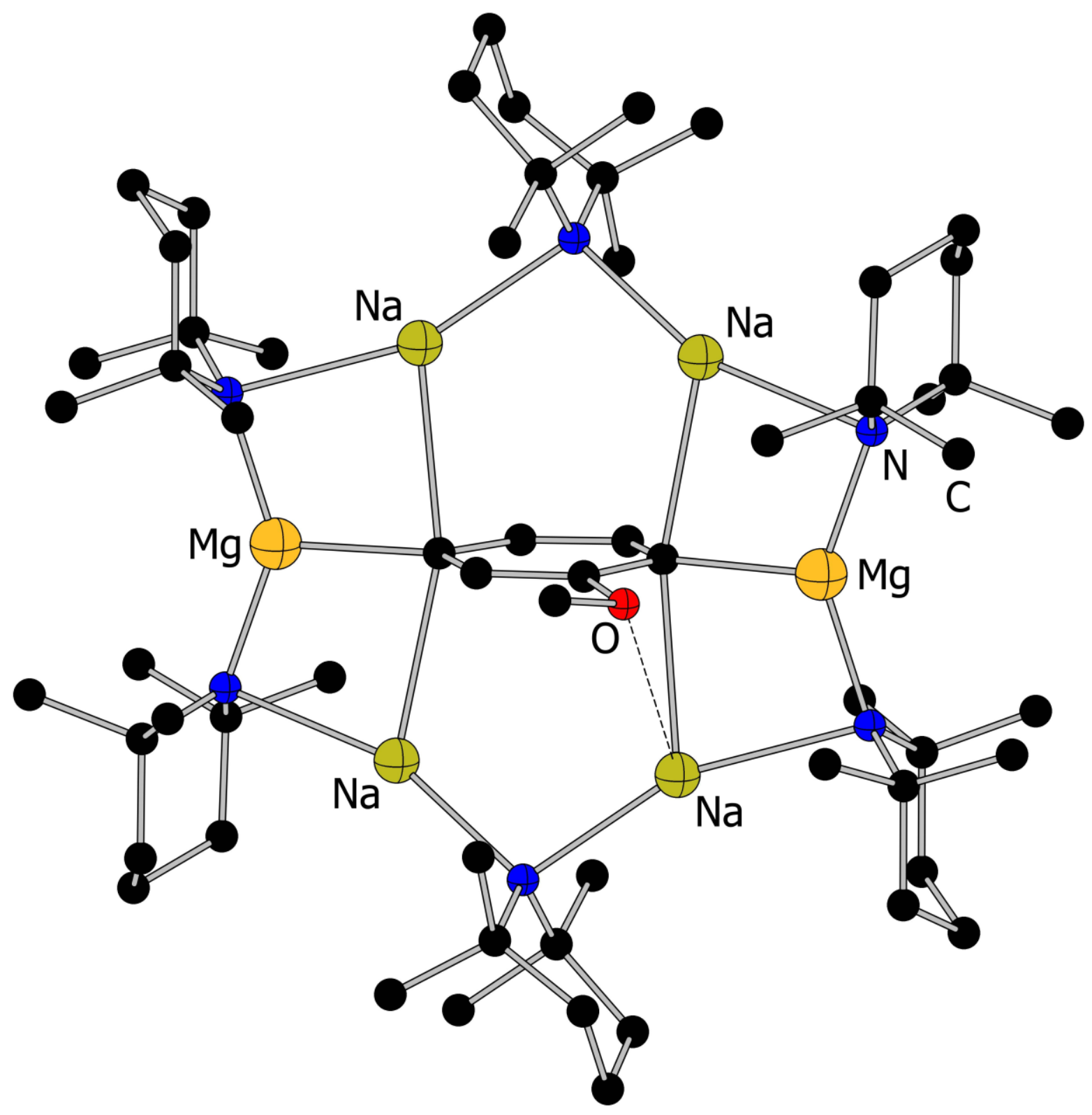

Fig. 3. Molecular structure of $\left[\mathrm{Na}_{4} \mathrm{Mg}_{2}(\mathrm{TMP})_{6}\left(\mathrm{C}_{6} \mathrm{H}_{3} \mathrm{OMe}-2,5\right)\right]$ 5a. Hydrogen atoms and one disordered component of both one TMP ligand and anisole moieties have been omitted for clarity. The dashed line illustrates a $\mathrm{Na} \cdots \mathrm{O}$ contact. 
$\mathrm{Mg}$ atoms within the 12-atom metal-amide ring occupy these deprotonated sites consistent with dimagnesiation of anisole. ${ }^{1} \mathrm{H}$ NMR spectroscopic data of both the isolated solid and reaction mixture show that the dimagnesium-tetrasodium hexanuclear ring is retained in $c y c-\mathrm{C}_{6} \mathrm{D}_{12}$ solution (25). The observation of only one set of anisolyl resonances confirmed that double deprotonation has occurred regioselectively at the 2,5-positions of anisole, the sole regioisomer formed. By treating in-situ solutions of 5a with iodine/THF or carbon dioxide then water, 1,4diiodo-2-methoxybenzene (6a') and 2-methoxyterephthalic acid (6a'') were isolated respectively (entry 2).

Subjecting (methoxymethyl)benzene (4b), tert-butoxybenzene (4c), (trifluoromethyl)benzene (4d), $N, N$-diisopropylbenzamide (4e), 4,4-dimethyl-2-phenyl-4,5-dihydrooxazole (4f) and phenyl- $N, N$-diethyl- $O$-carbamate $(\mathbf{4 g})$ to $\mathbf{2}_{\mathrm{Bu}}$ also gave 2,5-dimetalated intermediates in excellent yields (25). Quenching them with electrophiles gave the respective tri-substituted arenes in good to excellent isolated yields (Table 1).

In contrast, reaction of $\mathbf{2}_{\mathrm{Bu}}$ with $N, N$-dimethylaniline (7a) and $N, N$-diisopropylaniline (7b) (Table 2) induced selective 3,5-metalation of the substrate evidenced through two singlets in a 2:1 integration ratio in the arene region of ${ }^{1} \mathrm{H}$ NMR spectra of organometallic intermediates $\mathbf{8 a}$ and $\mathbf{8 b}$. X-ray diffraction studies of crystalline of $\mathbf{8 a}(91 \%$ yield) revealed a structure resembling $\mathbf{5 a}$, but with the aniline guest deprotonated in the 3,5-positions. This example of directed meta-meta' metalation $(\mathrm{D} m m \mathrm{M})$ completely overrides the conventional DoM effect observed in the anilines. $\mathbf{8 a}$ and $\mathbf{8 b}$ could be converted to their respective diiodo-complexes in good yields by treatment with iodine/THF (Table 2). 
Table 2. Regioselective 3,5-dimagnesiation of DG-substituted aryl substrates and subsequent electrophilic addition reaction.

Entry Substrate

* Metalation conditions (temperature, time). $\dagger$ Extension of 3,5-dimetalation determined by NMR spectroscopy. + Isolated yield. 


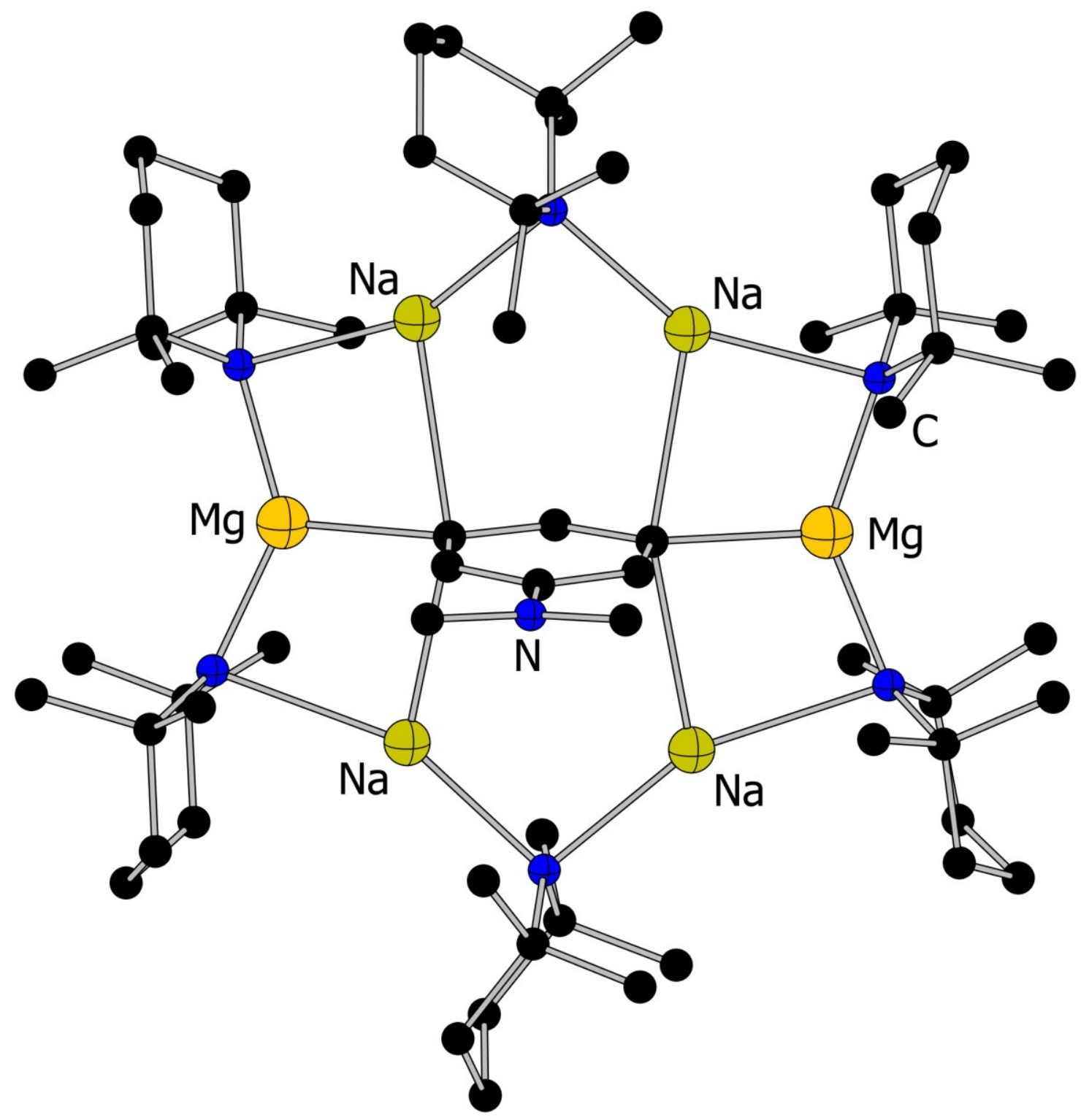

Fig. 4. Molecular structure of $\left[\mathrm{Na}_{4} \mathrm{Mg}_{2}(\mathrm{TMP})_{6}\left(\mathrm{C}_{6} \mathrm{H}_{3} \mathrm{NMe}_{2}-3,5\right)\right]$ 8a. Hydrogen atoms have been omitted for clarity.

X-ray data (Fig. 4) reveal that the anilino-N atom in 8a exhibits planar $\mathrm{sp}^{2}$ hybridisation, allowing conjugation of its lone pair into the aromatic system. Consequently, hindered rotation about the $\mathrm{N}-\mathrm{C}_{i p s o}$ bond effectively results in the methyl groups offering permanent steric protection to the ortho-positions, thus altering the metalation regioselectivity from 2,5- to 3,5for steric reasons. To pursue this idea further we treated 1 with the non-DoM directing $t$ butylbenzene (7c). Unlike the anilines, ortho-protection is not fixed, but we posited that the additional methyl group adjacent to the ipso-C may provide a similar ortho-protection. 
Quenching the reaction with iodine/THF, gave the predicted 1,3,5-substituted arene 1-(tertbutyl)-3,5-diiodobenzene (9c) (67\% isolated yield).

The Dom $\mathrm{M}$ and Dmm M concepts established here appear influenced by both electronic and steric effects. Firstly, consistent with DoM chemistry, strong DG-containing arenes require shorter reaction times and lower temperatures compared to those with weak DGs (Table 1, entries 6-8 vs entries 1-5) to achieve efficient dimetalation. Secondly, the spatial nature of the DG can redirect the deprotonations towards Dmm M breaking the dogma of DoM effects. However the major driver for dimetalation occurring in the first place seems to be the preorganized base structure having two butyl ligands on two magnesium atoms primed for executing deprotonation. Further proof of the greater influence of the base over the substrate comes from the observation that the regioselectivity of $\mathbf{2}_{\mathrm{Bu}}$ with toluene can be switched from Dom $\mathrm{M}$ to Dmm $\mathrm{M}$ by changing the alkyl component from butyl to trimethylsilylmethyl in $\mathbf{2}_{\text {Me3SiCH2 }}$ (32). Dimetalation is often seen as an unwanted side reaction complication in organic synthesis; whereas here it is a deliberate regioselective process controlled by the template nature of the bases $\left[\left\{\mathrm{KMg}(\mathrm{TMP})_{2}\left({ }^{\mathrm{n}} \mathrm{Bu}\right)\right\}_{6}\right] \mathbf{1}_{\mathbf{B u}}$ and " $\left[\mathrm{Na}_{4} \mathrm{Mg}_{2}(\mathrm{TMP})_{6}\left({ }^{\mathrm{n}} \mathrm{Bu}\right)_{2}\right]$ " $\mathbf{2}_{\mathbf{B u}}$. This concept could have a vast scope not just for dimetalation but for metalation in general provided different template bases can be designed. A glimpse of this scope can be seen in the ring-cage hybrid structure of $\left.\left[\left\{\mathrm{Li}(\mathrm{TMP}) \mathrm{Li}\left(\mathrm{C}_{5} \mathrm{H}_{4}\right)\right\}_{4} \mathrm{Li}_{6}\left({ }^{\mathrm{n}} \mathrm{Bu}\right)_{2}\right]\right]$ prepared via a shape-selective synthesis from the molecular square $\left[\left\{\mathrm{Li}(\mathrm{TMP}) \operatorname{Li}\left(\mathrm{C}_{5} \mathrm{H}_{5}\right)\right\}_{4}\right]$ and butyllithium (33). This novel templation approach presently realises dimetalation reactions exhibiting dual ortho-meta' or meta-meta' regioselectivities but the principle it establishes bodes well for a broader scope of positional $\mathrm{C}-\mathrm{H}$ to $\mathrm{C}-\mathrm{M}$ transformations in the future. Rationally designing a range of template bases is the next challenge for the metalation community.

\section{References and Notes:}

1. M. R. Hickey, S. P. Allwein, T. D. Nelson, M. H. Kress, O. S. Sudah, A. J. Moment, S. D. Rodgers, M. Kaba, P. Fernandez, Org. Process Res. Dev. 9, 764-767 (2005).

2. M. Schlosser, Organometallics in Synthesis Third Manual. M. Schlosser, Ed., (John Wiley \& Sons, Inc., Hoboken, New Jersey, 2013).

3. P. Beak, V. Snieckus, Acc. Chem. Res. 15, 306-312 (1982).

4. T. K. Macklin, V. Snieckus, in Handbook of C-H Transformations, G. Dyker, Ed. (WILEY-VCH, Weinheim, 2005), vol. 1, pp. 106-118.

5. V. Snieckus, Chem. Rev. 90, 879-933 (1990).

6. M. C. Whisler, S. MacNeil, V. Snieckus, P. Beak, Angew. Chem., Int. Ed. 43, 2206-2225 (2004).

7. H. Gilman, R. L. Bebb, J. Am. Chem. Soc. 61, 109-112 (1939).

8. G. Wittig, U. Pockels, H. Droge, Ber. Dtsch. Chem. Ges. 71, 1903-1912 (1938).

9. P. Beak, R. A. Brown, J. Org. Chem. 42, 1823-1824 (1977).

10. J. Mortier, J. Moyroud, B. Bennetau, P. A. Cain, J. Org. Chem. 59, 4042-4044 (1994).

11. M. Kauch, D. Hoppe, Synthesis, 1578-1589 (2006).

12. M. Kauch, D. Hoppe, Synthesis, 1575-1577 (2006).

13. T. K. Macklin, V. Snieckus, Org. Lett. 7, 2519-2522 (2005).

14. C. Metallinos, S. Nerdinger, V. Snieckus, Org. Lett. 1, 1183-1186 (1999).

15. B. Haag, M. Mosrin, H. Ila, V. Malakhov, P. Knochel, Angew. Chem., Int. Ed. 50, 97949824 (2011). 
16. A. Krasovskiy, V. Krasovskaya, P. Knochel, Angew. Chem., Int. Ed. 45, 2958-2961 (2006).

17. R.-Y. Tang, G. Li, J.-Q. Yu, Nature 507, 215-220 (2014).

18. D. Leow, G. Li, T.-S. Mei, J.-Q. Yu, Nature 486, 518-522 (2012).

19. A. J. Martínez-Martínez, D. R. Armstrong, B. Conway, B. J. Fleming, J. Klett, A. R. Kennedy, R. E. Mulvey, S. D. Robertson, C. T. O'Hara, Chem. Sci. 5, 771-781 (2014).

20. A. R. Kennedy, S. M. Leenhouts, J. J. Liggat, A. J. Martinez-Martinez, K. Miller, R. E. Mulvey, C. T. O'Hara, P. O'Keefe, A. Steven, Chem. Commun. 50, 10588-10591 (2014).

21. W. Bauer, D. Seebach, Helv. Chim. Acta 67, 1972-1988 (1984).

22. R. E. Mulvey, Acc. Chem. Res. 42, 743-755 (2009).

23. P. Alborés, L. M. Carrella, W. Clegg, P. García-Álvarez, A. R. Kennedy, J. Klett, R. E. Mulvey, E. Rentschler, L. Russo, Angew. Chem., Int. Ed. 48, 3317-3321 (2009).

24. C. Schade, W. Bauer, P. V. Schleyer, J. Organomet. Chem. 295, C25-C28 (1985).

25. Materials and methods are available as supplementary material on Science Online

26. K. Flick, E. Frankus. (US3652589A, 1972).

27. M. Protiva, Drugs Fut. 16, 911-916 (1991).

28. W. Bauer, P. V. Schleyer, J. Am. Chem. Soc. 111, 7191-7198 (1989).

29. S. T. Chadwick, R. A. Rennels, J. L. Rutherford, D. B. Collum, J. Am. Chem. Soc. 122, 8640-8647 (2000).

30. S. Harder, J. Boersma, L. Brandsma, J. A. Kanters, J. Organomet. Chem. 339, 7-15 (1988).

31. J. M. Saa, P. M. Deya, G. A. Suner, A. Frontera, J. Am. Chem. Soc. 114, 9093-9100 (1992).

32. V. L. Blair, L. M. Carrella, W. Clegg, B. Conway, R. W. Harrington, L. M. Hogg, J. Klett, R. E. Mulvey, E. Rentschler, L. Russo, Angew. Chem., Int. Ed. 47, 6208-6211 (2008).

33. A. A. Fyfe, A. R. Kennedy, J. Klett, R. E. Mulvey, Angew. Chem., Int. Ed. 50, 7776-7780 (2011).

34. E. Hevia, A. R. Kennedy, R. E. Mulvey, S. Weatherstone, Angew. Chem., Int. Ed. 43, 1709-1712 (2004).

35. B. Gehrhus, P. H. Hitchcock, A. R. Kennedy, M. F. Lappert, R. E. Mulvey, P. J. A. Rodger, J. Organomet. Chem. 587, 88-92 (1999).

36. W. M. Seganish, P. DeShong, J. Org. Chem. 69, 6790-6795 (2004).

37. A. Antoft-Finch, T. Blackburn, V. Snieckus, J. Am. Chem. Soc. 131, 17750-17752 (2009).

38. G. M. Sheldrick, Acta Cryst. A. A64, 112 (2008).

39. T. Claridge, Editor, High-Resolution NMR Techniques in Organic Chemistry. (Elsevier: Boston, ed. 2nd, 2009).

40. M. C. Cassani, Y. K. Gun'ko, P. B. Hitchcock, M. F. Lappert, F. Laschi, Organometallics 18, 5539-5547 (1999).

41. H. E. Zimmerman, Acc. Chem. Res. 45, 164-170 (2011).

42. T. Mangel, A. Eberhardt, U. Scherf, U. H. F. Bunz, K. Müllen, Macromol. Rapid Commun. 16, 571-580 (1995).

43. Y. Chen, L. Chen, W. Zhou, D. Zha, D. Zhou, F. Bai, M. Wan, Synth. Met. 159, 16491656 (2009).

44. A. Hafner, S. Bräse, Angew. Chem., Int. Ed. 51, 3713-3715 (2012). 
45. J.-J. Hwang, J. M. Tour, Tetrahedron 58, 10387-10405 (2002).

46. Y. Miura, Y. Ushitani, K. Inui, Y. Teki, T. Takui, K. Itoh, Macromolecules 26, 36983701 (1993).

47. M. Oki, in Topics in Stereochemistry. (John Wiley \& Sons, Inc., 1983), pp. 1-81.

48. J. Clayden, W. J. Moran, P. J. Edwards, S. R. LaPlante, Angew. Chem., Int. Ed. 48, 63986401 (2009).

49. G. Bringmann, A. J. Price Mortimer, P. A. Keller, M. J. Gresser, J. Garner, M. Breuning, Angew. Chem., Int. Ed. 44, 5384-5427 (2005).

50. M. P. Sibi, S. Chattopadhyay, J. W. Dankwardt, V. Snieckus, J. Am. Chem. Soc. 107, 6312-6315 (1985).

51. M. P. Sibi, V. Snieckus, J. Org. Chem. 48, 1935-1937 (1983).

Acknowledgments: We gratefully acknowledge financial support from the Royal Society (Wolfson research merit award to R.E.M.) and the EPSRC (Career Acceleration Fellowship, EP/J001872/1 and EP/L001497/1 to C.T.O.H.). Prof. Hevia and Dr. B. J. Fleming are also thanked for insightful discussions. We are also grateful to the EPSRC UK National Mass Spectrometry Facility (NMSF), Swansea for collecting our mass spectral data. Metrical data for $\mathbf{5 a}$ and $\mathbf{8 a}$ are freely available from the Cambridge Crystallographic Database Centre (CCDC-1017351 and CCDC-1017352, respectively).

\section{Supplementary Materials:}

Materials and Methods

Figures S1-S80

Tables S1-S3

Supplementary Text 